\title{
The Carotenoid Pigments of White-fleshed Sweet Potatoes $^{1}$
}

\author{
Franklin W. Martin ${ }^{2}$
}

\begin{abstract}
Carotenoid pigments of 14 white-fleshed sweet potatoes were found to consist of phytofluene, $\zeta$-carotene, neurosporene, and $\beta$-zeacarotene. These are precursors of beta-carotene, the principal carotenoid of normal orangefleshed sweet potatoes. Green color of cooked sweet potatoes was associated with an epoxide of the above carotenoids that is blue in acidic solution. Sweet potatoes that are yellow are milder in flavor than orange sweet potatoes, yet still are somewhat active as provitamin A.
\end{abstract}

\section{INTRODUCTION}

The edible storage roots of sweet potato, Ipomoea batatas L. Poir., often contain carotenoid pigments. The deep orange color of the roots of many varieties is caused by the principal carotenoid, $\beta$-carotene. In evaluations of the sweet potato this substance has been emphasized, and is now even measured by reference to a color standard with a commercial color meter (8). Although other carotenoids are known to occur in the sweet potato, there has been little interest in their identification. Matlock (9) found small quantities of anthoxanthins, one of which was identified as violoxanthin. Ezell and Wilcox (4) found that as the percentage of carotenoids decreases, the fraction that is not $\beta$-carotene increases.

The roots of some sweet potato varieties are not orange. Although loosely called "white-fleshed," these vary from white to cream, light yellow, or light orange. Cooking almost always intensifies the color. The cooked root may be white, gray, greenish, yellowish, yellow, or orange. Since white-fleshed sweet potatoes are usually preferred as food in the tropics, because they do not have a carrot-like flavor, it is of considerable interest to know what pigments they contain.

The significance of carotenoid pigments in foods is that some are converted in animals and man to vitamin $\mathrm{A}$. The minimum vitamin $\mathrm{A}$ requirements of an adult male is 5,000 units of activity (10). This is equivalent to $0.273 \mathrm{mg}$ of $\beta$-carotene. Nevertheless, not all $\beta$-carotene or other active carotenoids ingested are efficiently used. At low levels of intake at least 3 times the amount of $\beta$-carotene is necessary and up to 8 times this amount of carotene is recommended (2). As carotenoid intake increases, efficiency of use decreases. Therefore, low level intake of carotenoids is preferred in the diet for efficient conversion.

${ }^{1}$ Manuscript submitted to Editorial Board September 10, 1982.

${ }^{2}$ Research Horticulturist, Mayagüez Institute of Tropical Agriculture Research Station, ARS, USDA, Mayagüez, P.R. 
A normal serving of sweet potato, $150 \mathrm{~g}$, often contains several times more vitamin A activity than the recommended daily allowance. For example, the dry-fleshed Jersey variety Orange Little Stem contains about 12,500 units (1). The $\beta$-carotene content of Porto Rico varies from 3.16 to $7.01 \mathrm{mg} / 100 \mathrm{~g}$, wet weight basis (7). Newly developed varieties contain even more $\beta$-carotene. Very strong orange color (high $\beta$-carotene content) is a principal characteristic in judging sweet potato quality (11).

It is unusual to find a food, $100 \mathrm{~g}$ of which supplies all of the minimum daily requirement of any nutrient. Orange-fleshed sweet potatoes have more than enough vitamin A activity for normal human use.

The purpose of this study was to identify the carotenoids of some socalled white-fleshed sweet potatoes, with particular reference to their potential value as sources of vitamin A activity.

\section{MATERIALS AND METHODS}

Fifteen "white-fleshed" varieties or breeding lines of sweet potato were grown at Mayagüez, Puerto Rico, and fresh storage roots were used for all tests.

Sections of storage roots were peeled, cut into small pieces, and in a household blender, $100 \mathrm{~g}$ was ground with $100 \mathrm{ml}$ acetone. Then $100 \mathrm{ml}$ petroleum ether was blended into the suspension. The resulting mixture was permitted to rest $15 \mathrm{~min}$, during which time most of the starch and congealed gums were precipitated. The solvent mixture, with all the yellow pigments, was then filtered.

Washing the petroleum ether mixture with three changes of water removed the acetone. The mixture was then rid of traces of water with anhydrous sodium sulphate, refiltered, and stored in a nitrogen atmosphere.

The petroleum ether mixture with the pigments was evaporated in a warm-water bath with a constant stream of nitrogen. Heptane was added to dissolve the pigments. The mixture was then separated into phases by Goodwin's method (5). An equal volume of $90 \%$ methanol was added and the mixture shaken and allowed to separate into phases. The upper phase (heptane) was washed several times with the same methanolic solution until the wash solution was clear; the lower phase was likewise extracted with added heptane. To the heptane phase was then added an equal volume of $95 \%$ methanol, and the phase separation was repeated. In some cases a phase separation was also achieved by adding acetone to the heptane solution.

Alumina was mixed with heptane and poured as a slurry into chromatographic columns. Pigment mixtures were concentrated in a warm water bath with a stream of nitrogen and applied to the upper parts of the column. The columns were developed either with acetone or ether, 
and the pigment bands were captured in flasks, evaporated with nitrogen, and suspended in heptane. Absorption spectra were obtained with a Beckman Acta-C-III spectrophotometer. ${ }^{3}$ The pigments were identified from their absorption spectra, by means of published values (3). One compound with unusual spectrum was treated with $\mathrm{HCl}$ and retested for absorption.

\section{RESULTS}

The uncooked flesh of the sweet potato roots ranged in color from white to orange (table 1). Color was intensified by cooking, and a few cooked sweet potato roots were greenish or green. On extraction and phase separation, the heptane phase was yellow or almost orange of medium to high intensity. The 90 and 95 percent methanol phases were light yellow or clear, and the acetone phase was pale yellow, green, or blue. The nutritionally significant pigments, the carotenes, were expected to be in the heptane phase and were studied in detail. The xanthophylls with 2 or more free hydroxy or keto group, in 90 percent methanol, and with one free hydroxy or keto groups in 95 percent methanol, are not of nutritional significance and were not studied further. The acetone phase contained epoxy derivatives of the carotenes. The yellow pigment in this phase was converted to blue by acid treatment, and reconverted to yellow with $\mathrm{NaOH}$.

Column chromatography with alumina separated one or two principal pigments and traces of 1-3 more, often mixed with the principal bands. Characteristic absorption bands were found associated with the chromatographic fractions (table 2). The relative amounts of the fractions were determined from the intensity of the color of the eluent as well as relative heights of the absorption peak.

The identification of all fractions were easily identified with published values (3). The substances found, phytofluene, $\zeta$-carotene, neurosporene, $\beta$-zeacarotene, and $\beta$-carotene are in the presumed chain of synthesis of $\beta$-carotene (table 3 ). However, no $\gamma$-carotene, the presumed intermediate between $\beta$-zeacarotene and $\beta$-carotene was found.

The principal carotene was $\beta$-carotene in six varieties, $\beta$-zeacarotene in 7 varieties and neurosporene in 2 varieties. Most also contained traces of the biosynthetic intermediates leading to synthesis of the principal compound.

Traces of the epoxy derivatives were found in the acetone fraction.

\footnotetext{
${ }^{3}$ Trade names in this publication are used only to provide specific information. Mention of a trade name does not constitute a warranty of equipment or materials by the Agricultural Experiment Station of the University of Puerto Rico, nor is this mention a statement of preference over other equipment or materials.
} 
TABLE 1.-Color of sweet potato roots and of their carotenoid extracts in various solutions

\begin{tabular}{|c|c|c|c|c|c|}
\hline Cultivar & $\begin{array}{l}\text { Color of } \\
\text { uncooked } \\
\text { root }\end{array}$ & $\begin{array}{l}\text { Color of } \\
\text { cooked } \\
\text { root }\end{array}$ & $\begin{array}{l}\text { Color of } \\
\text { heptane } \\
\text { phase }^{2}\end{array}$ & $\begin{array}{c}\text { Color of } \\
90 \% \text { methanol } \\
\text { phase }^{2}\end{array}$ & $\begin{array}{c}\text { Color of } \\
95 \% \text { methanol }^{\text {phase }}{ }^{2}\end{array}$ \\
\hline Cubana & Cream & Cream & Yellow (7) & Yellow (1) & - \\
\hline Dominicana & Cream & Cream & Green (8) & Yellow (3) & Yellow (3) \\
\hline Rojoblanco & Cream & Cream & Yellow (7) & Yellow (2) & - \\
\hline Teardrop ${ }^{1}$ & White & Greenish & Yellow-green (7) & Yellow (2) & Yellow (1) \\
\hline Yellow Jersey & Cream & Yellow & Yellow (7) & Yellow (2) & - \\
\hline $60^{1}$ & Orange & Orange & Orange (9) & Yellow (3) & 一 \\
\hline $97^{1}$ & White & Greenish & Green (7) & Yellow (3) & - \\
\hline $123^{1}$ & White & Cream & Yellow (6) & - & - \\
\hline $136^{1}$ & Yellow & Yellow-green & Yellow (5) & Yellow (3) & - \\
\hline $203^{1}$ & White & Yellow & Yellow (5) & Yellow (1) & 一 \\
\hline $209^{1}$ & Cream & Yellow & Yellow (7) & Yellow (2) & 一 \\
\hline $211^{1}$ & Cream & Yellow & Yellow (8) & Yellow (1) & - \\
\hline $256^{1}$ & Light-yellow & Yellow & Yellow (9) & Yellow (1) & - \\
\hline Selection A & Yellow & Dark yellow & Yellow (9) & Yellow (6) & Yellow (1) \\
\hline Selection B & Yellow-orange & Orange & Yellow-orange (9) & Yellow (9) & Yellow (1) \\
\hline
\end{tabular}

${ }^{1}$ Clones from seedlings grown in Mayagüez.

${ }^{2}$ Rated visually from 1 to 9 in intensity. 
TABLE 2.-Characteristic absorption in heptane of principal carotenoids from "white-fleshed" sweet potatoes ${ }^{1}$

\begin{tabular}{|c|c|c|c|c|c|}
\hline \multirow{2}{*}{ Cultivar } & \multicolumn{5}{|c|}{ Absorption wavelengths } \\
\hline & 332348368 & 379400425 & 418442470 & 398424449 & $(426) 448480$ \\
\hline Cubana & - & $\mathrm{X}$ & $\mathrm{X}$ & $\mathrm{XXX}$ & - \\
\hline Dominicana & $\mathrm{X}$ & $\mathrm{XX}$ & - & $\mathrm{XXX}$ & - \\
\hline Rojoblanco & - & $\mathrm{X}$ & $\mathrm{X}$ & $\mathrm{XXX}$ & - \\
\hline Teardrop & - & $\mathrm{X}$ & - & XX & - \\
\hline Yellow Jersey & - & $\mathrm{X}$ & $\mathrm{X}$ & $\mathrm{XXX}$ & - \\
\hline 60 & - & - & - & - & $\mathrm{XXXX}$ \\
\hline 97 & - & $\mathrm{X}$ & $\mathrm{XXX}$ & - & - \\
\hline 123 & - & $\mathrm{x}$ & $\mathrm{XXX}$ & - & 一 \\
\hline 136 & - & - & 一 & $\mathrm{XXX}$ & - \\
\hline 203 & - & - & - & - & $\mathrm{XX}$ \\
\hline 209 & - & $\mathrm{X}$ & - & - & $\mathrm{XXX}$ \\
\hline 211 & - & - & - & - & $\mathrm{XXX}$ \\
\hline 256 & - & - & - & - & $\mathrm{XXX}$ \\
\hline Selection A & - & $\mathrm{X}$ & $\mathrm{X}$ & $\mathrm{XXX}$ & - \\
\hline Selection B & - & $\mathrm{X}$ & $\mathrm{X}$ & XX & $\mathrm{XXX}$ \\
\hline
\end{tabular}

${ }^{1}$ Relative amounts were visually estimated and are recorded as number of X's. 
These changed to deep blue when treated with a drop of $\mathrm{HCl}$. This color reaction was reversed with $\mathrm{KOH}$ solution.

\section{DISCUSSION}

The results show that so-called white-fleshed sweet potatoes contain carotenes which range from colorless through yellow to orange. These pigments constitute a biosynthetic series (5). However, the process of synthesis terminates in neurosporene in some, in $\beta$-zeacarotene in others, and in $\beta$-carotene in others. When large amounts of $\beta$-zeacarotene are present, sweet potatoes are slightly to light yellow before cooking, and deeply yellow after boiling.

Not all carotenes are sources of provitamin A activity. Among the requirements for such activity is the presence of one unsubstituted $\beta$ ionine ring. $\beta$-carotene contains two such rings. $\beta$-zeacarotene contains only one such ring and its provitamin A activity is estimated to be 20 to

TABLE 3.-Carotenoid compounds identified in "white-fleshed" sweet potatoes and their characteristic ultraviolet absorption

\begin{tabular}{lcccccc}
\hline \multicolumn{1}{c}{ Compound } & \multicolumn{3}{c}{$\begin{array}{c}\text { Absorption in hexane } \\
\text { or petroleum } \\
\text { ether }\end{array}$} & & \multicolumn{2}{c}{ Absorption in heptane ${ }^{2}$} \\
\hline Phytofluene & 331 & 348 & 367 & 332 & 348 & 368 \\
$\zeta$-carotene & 378 & 400 & 425 & 379 & 400 & 425 \\
Neurosporene & 416 & 440 & 470 & 418 & 442 & 470 \\
$\beta$-zeacarotene & 406 & 428 & 454 & 402 & 427 & 450 \\
$\beta$-carotene & $(425)$ & 451 & 482 & $(426)$ & 448 & 480 \\
\hline
\end{tabular}

${ }^{1}$ Absorptions according to Davies (1965).

${ }^{2}$ Absorptions in these experiments.

40 percent of that of $\beta$-carotene (2). On the other hand, the very pale compound, neurosporene, has no vitamin A activity.

In the tropics many people prefer to eat the so-called white-fleshed sweet potatoes, including yellow types because they do not like the taste of the orange-fleshed types (6). These results show that yellow sweet potatoes with their milder flavor contain a carotenoid that is also useful as provitamin A. Thus, it is possible to have sweet potatoes that satisfy tropical palates without sacrifice of all vitamin A activity.

The disagreeable green color of some cooked sweet potatoes is due to epoxides of one or more carotenes. These compounds are sensitive to $\mathrm{pH}$ and are blue in acidic solution. They appear green mixed with a yellow pigment. Color of such sweet potatoes improves if they are cooked in slightly alkaline water. 


\section{RESUMEN}

Se encontró que los pigmentos carotenoides de 14 batatas tipo blanco consistieron de fitoflueno, $\zeta$-caroteno, neurosporeno y $\beta$-zeacaroteno. Estos son precursores de $\beta$-caroteno, el carotenoide principal de las variedades de batata anaranjada. El color verde de las batatas cocidas estaba asociado con un epóxido de los carotenoides arriba mencionados. Los epóxidos son sensitivos al pH; en una solución ácida son azules. Las amarillas son de un sabor menos pronunciado que las anaranjadas, pero aun asi son algo activas como provitamina $\mathrm{A}$.

\section{LITERATURE CITED}

1. Adams, C. F., 1975. Nutritive value of American foods, Agriculture Handbook 456, ARS, USDA, Washington, D.C.

2. Baiernfeind, J. C., 1972. Carotenoid vitamin A precursors and analogs in foods and feeds, J. Agr. Food Chem. 20: 456-73.

3. Davies, B. H., 1965. Analysis of carotenoid pigments, In: Chemistry and Biochemistry of Plant Pigments. T. W. Goodwin (Ed), London, Academic Press, pp. 489-532.

4. Ezell, B. D. and Wilcox, M. S., 1946. The ratio of carotene to carotenoid pigments in sweet potato varieties, Science 103: 193-94.

5. Goodwin, T. W., 1975. Biosynthesis, In: Carotenoids. Karrer, P. and Jucker, E. (Ed), Elsevier, New York, pp. 577-636.

6. Haddock, D. and Mirabel, R. A., 1953. Preferencias del consumidor por la batata. Bol. 110, Esta. Exp. Agrí. Univ. P. R.

7. Kimbrough, N. D., Fieger, A. E. and Lewis, H., 1946. Effect of date of planting and time of harvest on the carotene content of the Porto Rico variety, Proc. Am. Soc. Hort. Sci. 47: 400-02.

8. Lauber, J. J., Taylor, G. A. and Drinkwater, W. O., 1967. The use of tristimulus colorimetry for the estimation of carotenoid content of raw sweet potato roots, Proc. Am. Soc. Hort. Sci. 91: 472-77.

9. Matlock, M. B., 1937. The carotenoid pigments of the sweet potato (Ipomoea batatas Poir). J. Wash. Acad. Sci. 27: 493-95.

10. National Research Council, 1974. Recommended Dietary Allowances, 8th ed, National Academy of Sciences-National Research Council, Washington, D.C.

11. University of Georgia, 1980. Sweet Potato Quality, Southern Cooperative Series, Athens, Georgia. 